\title{
Commentary
}

\section{Strategies for the prevention of malaria in pregnancy in Indonesia in the COVID-19 pandemic era}

\author{
Andre Prawira-Putra*, Theda Lukito, Rukhsana Ahmed
}

Clinesia-CRO, Komplek Ruko Diamond Boulevard I No.7, Cengkareng Timur, Jakarta, Indonesia

Received: 28 May 2020

Accepted: 12 June 2020

\section{*Correspondence:}

Dr. Andre Prawira-Putra,

E-mail: aputra@alumni.harvard.edu

Copyright: (C) the author(s), publisher and licensee Medip Academy. This is an open-access article distributed under the terms of the Creative Commons Attribution Non-Commercial License, which permits unrestricted non-commercial use, distribution, and reproduction in any medium, provided the original work is properly cited.

\section{INTRODUCTION}

Malaria is one of the oldest infectious disease that continues to affect annually more than 200 million people globally. ${ }^{1}$ Pregnant women are the second most vulnerable group to malaria, besides children. A pregnant woman with malaria risks detrimental harm to herself and to her child resulting in adverse pregnancy outcomes. These adverse outcomes contribute to maternal, neonatal and infant morbidity and mortality. It is essential to protect pregnant women from malaria to improve the public health burden in malaria endemic countries.

Indonesia is one of the several countries that have set a target of zero malaria by 2030. While efforts to strengthen malaria elimination goals are needed, the world has been taken under the grip of the newly emergent coronavirus disease-2019 (COVID-19) which is caused by the highly contagious severe adult respiratory syndrome coronavirus-2 (SARS-CoV-2). ${ }^{2}$ The rapid global spread of COVID-19 led to the World Health Organization (WHO) declaring a pandemic in March $2020 .^{3}$ At the end of May 2020, an estimated 368,945 people worldwide had died from COVID-19. ${ }^{4}$ Due to the enormity of the pandemic problem, governments and public health systems across the world are focused on "flattening the curve" of the COVID-19. Although the pandemic is a priority, it is important that existing public health programs such as malaria control efforts are on track to reach the elimination targets set by the governments.

Unlike malaria, COVID-19 is a new disease. The limited data on COVID-19 indicates that pregnant women are not at any greater risk to COVID-19 than the general population. ${ }^{5,6}$ Likewise, current evidence shows there is no increased risk of miscarriage or vertical transmission associated with COVID-19 in pregnancy. ${ }^{6,7}$ Although the disease is evolving, information on the impact of COVID19 on pregnant women and their babies is reassuring in contrast to malaria in pregnancy. Another noteworthy point is yet there is no data on coinfection of COVID-19 and malaria in pregnant women. Should this occur, it would add double burden to the already overstretched health systems in resource limited malaria endemic countries. It is therefore crucial not to let malaria in pregnancy prevention slip into the shadow of the COVID19 control efforts. Here we highlight malaria in pregnancy prevention strategies that could be considered in Indonesia in the COVID-19 pandemic and postpandemic era.

\section{Prevention strategies}

In the last decade Indonesia has shown tremendous improvement in their malaria elimination program. Annual parasite incidence, which is the number of new malaria infections per year per 1000 population, decreased from 2.89 in 2007 to 0.9 in $2017 .{ }^{8}$ Out of the 450 districts in the country, 266 are now free from malaria with nearly three fourth of the population living in malaria free areas. These progressive strides are due to the concerted efforts made by the stakeholders at all levels following the National Ministerial Decree on malaria elimination passed in 2009. Yet, more needs to be done to reach the 2030 malaria elimination target set by WHO.

Malaria in pregnancy is an example of both gender equality, good health and well-being goals in the 
sustainable development goals. ${ }^{9}$ Approximately 6.4 million Indonesian women every year are still risking their pregnancies to malaria exposure. ${ }^{10}$ Infections from both Plasmodium falciparum and Plasmodium vivax, the two most prevalent malaria species in Indonesia, in pregnancy are associated with severe maternal anemia, fetal loss, preterm births and low birth weight babies. ${ }^{11,12}$

To combat the burden of malaria in pregnancy, in 2006, Indonesia introduced screening and treatment of malaria in pregnancy which is being delivered as a single screen and treat (SST) strategy. ${ }^{13}$ This means that every pregnant woman who visits a healthcare worker in a malaria endemic area, will be tested for malaria during her first antenatal visit. Malaria positive women gets treated immediately with the artemisinin combination drug, dihydroartemisinin-piperaquine (DP). But those women with negative results will receive no further testing for the rest of their pregnancy, if they remain asymptomatic.

SST strategy may sound solid, but one major limitation is obvious from the outset. SST can only detect infections happening during the first antenatal contact with a health worker. In other words, malaria infections occurring later in pregnancy after the first antenatal visit will be missed. Although SST has reached a high coverage of the population, it has not served its purpose to screen and treat malaria occurring throughout the duration of pregnancy. ${ }^{14,15}$ Fifteen years of SST strategy have led to preventable risks for many mothers and newborn babies as well as expensive tradeoffs for the future generations.

There are two other strategies commonly practiced elsewhere: intermittent preventive treatment (IPT) and intermittent screening and treatment (IST). ${ }^{11,16}$ IPT consists of giving a dose of sulfadoxine-pyrimethamine to pregnant women without testing for malaria at three scheduled antenatal visits during the second and third trimesters. This WHO-recommended strategy has been proven effective in reducing the harmful effects of malaria in pregnancy in African countries. The other strategy, IST consists of testing pregnant women with malaria rapid diagnostic testing (RDT) at every scheduled antenatal visit started anytime during pregnancy.

The above described three strategies has been researched in Indonesia under the clinical trial screen and treat or prevent malaria in pregnancy (STOPMIP), and published in 2019. ${ }^{11}$ The study group looked at how the three strategies of IPT, IST and SST using DP differed in the reduction of malaria during pregnancy and the efficacy and safety of DP for malaria prevention in pregnancy in Indonesia. The study recruited more than 2000 pregnant women in Sumba, a low malaria transmission district and in Papua, a moderately high malaria endemic district. The researchers found that IPT with DP was more effective in reducing malaria in pregnancy in Papua, while screening strategies reduced the malaria infections at delivery in Sumba. This new evidence comes as a wake-up call for policy makers to shift from a one-size-fits-all strategy for malaria in pregnancy in Indonesia.

Malaria in pregnancy data in Indonesia are scarce. Often malaria infection in pregnant women are either subclinical or asymptomatic and it adds to many cases being underdiagnosed and underreported. This is partly due to the difficulty in detecting the malaria parasite in maternal blood during pregnancy with the currently available RDTs or by conventional microscopy. These asymptomatic pregnant women are also a reservoir for malaria transmission and adds to the difficulties of malaria elimination. Considering these factors, the policy makers face a challenging decision regarding which rapid test to use as a point-of-care test to accurately detect malaria in pregnancy.

The IPT strategy does not require diagnostic test kits or skilled staff to perform microscopy and would be an easier strategy to implement. The new IPT drug such as DP are also associated with better outcome and the dosing is predetermined according to the weight of the woman. ${ }^{11}$ The fixed dose combination of DP enables lessspecialized personnel such as midwives to prescribe the drugs at the predetermined dosage to antenatal women. It also enables stakeholders to deploy these personnel more widely in remote areas.

For the IPT strategy to work effectively, it is essential to scale up the availability of the drugs at health facilities offering antenatal care in malaria endemic areas. Efforts to improve antenatal visits and compliance with drug intake is necessary to implement IPT as a public health intervention for malaria control in pregnancy. It can be achieved by reinforcing community socialization on the importance of antenatal visits, empowering the existing midwives and nurses in rural areas to prescribe drugs for IPT, and holding health promotion activities on the uptake of the drug when a woman is asymptomatic.

To stay on target for malaria elimination by 2030 with COVID-19 looming on the health systems, IPT is one strategy that could become the new normal for malaria in pregnancy prevention, at least in high malaria endemic areas in Indonesia. With reference to STOPMIP findings, IPT strategy is more feasible because it is easier for health workers and pregnant women to follow and less complicated to scale up implementation. Dr. Tedros Adhanom Ghebreyesus, Director-General of WHO, said in his speech last year, "The goal of eradicating malaria is supremely ambitious. But true progress only happens when we set goals that we think are out of reach" ${ }^{17}$ In echoing his spirit, setting objectives to combat malaria in pregnancy under the malaria elimination program could be the way forward to realize this dream in the COVID19 era.

\section{REFERENCES}

1. WHO. World malaria report 2019. Geneva: World Health Organization; 2019. Available at: 
https://www.who.int/publications/i/item/worldmalaria-report-2019. Accessed on 8 May 2020.

2. Rothan HA, Byrareddy SN. The epidemiology and pathogenesis of coronavirus disease (COVID-19) outbreak. J Autoimmunity. 2020: 102433.

3. Cucinotta D, Vanelli M. WHO declares COVID-19 a pandemic. Acta bio-medica: Atenei Parmensis. 2020;91(1):157-60.

4. Our World in Data. Coronavirus (Covid-19) Deaths $2020 . \quad$ Available at: https://ourworldindata.org/coronavirus. Accessed on 7 May 2020.

5. Favre G, Pomar L, Qi X, Nielsen-Saines K, Musso D, Baud D. Guidelines for pregnant women with suspected SARS-CoV-2 infection. Lancet Infect Dis. 2020;20(6):652-3.

6. Knight M, Bunch K, Vousden N, Morris E, Simpson $\mathrm{N}$, Gale $\mathrm{C}$, et al. Characteristics and outcomes of pregnant women hospitalised with confirmed SARS-CoV-2 infection in the UK: a national cohort study using the UK Obstetric Surveillance System (UKOSS). MedRxiv. 2020.

7. Yu N, Li W, Kang Q, Xiong Z, Wang S, Linet X, al. Clinical features and obstetric and neonatal outcomes of pregnant patients with COVID-19 in Wuhan, China: a retrospective, single-centre, descriptive study. Lancet Infect Dis. 2020.

8. Sitohang V, Sariwati E, Fajariyani SB, Hwang D, Kurnia B, Hapsari RK, et al. Malaria elimination in Indonesia: halfway there. Lancet Glob Health. 2018;6(6):604-6.

9. Swiss Medical Group. Malaria and the Sustainable Development Goals for 2030. 2018. Available at: https://endmalaria.org/about-malaria/malariasustainable-development-goals. Accessed on 06 May 2020.

10. Dellicour S, Tatem AJ, Guerra CA, Snow RW, ter Kuile FO. Quantifying the number of pregnancies at risk of malaria in 2007: a demographic study. PLoS Med. 2010;7(1):e1000221.

11. Ahmed R, Poespoprodjo JR, Syafruddin D, Khairallah C, Pace C. Efficacy and safety of intermittent preventive treatment and intermittent screening and treatment versus single screening and treatment with dihydroartemisinin-piperaquine for the control of malaria in pregnancy in Indonesia: a cluster-randomised, open-label, superiority trial. Lancet Infect Dis. 2019;19(9):973-87.

12. Poespoprodjo JR, Fobia W, Kenangalem E, Lampah DA, Warikar N, Seal A, et al. Adverse pregnancy outcomes in an area where multidrug-resistant plasmodium vivax and Plasmodium falciparum infections are endemic. Clin Infect Dis. 2008;46(9):1374-81.

13. National malaria control programme review: Republic of Indonesia. WHO Country Office Indonesia and $\mathrm{MoH}$ 2011. Available at: https://apps.who.int/iris/bitstream/handle/10665/253 960/9789791947749eng.pdf?sequence=1\&isAllowe $\mathrm{d}=\mathrm{y}$. Accessed on 7 May 2020.

14. Hill J, Landuwulang CUR, Ansariadi, Hoyt J, Burdam FH, Bonsapia I, et al. Evaluation of the national policy of single screening and treatment for the prevention of malaria in pregnancy in two districts in Eastern Indonesia: health provider perceptions. Malar J. 2018;17(1):309.

15. Webster J, Ansariadi, Burdam FH, Landuwulang CUR, Bruce J, Poespoprodjo JR, et al. Evaluation of the implementation of single screening and treatment for the control of malaria in pregnancy in Eastern Indonesia: a systems effectiveness analysis. Malar J. 2018;17(1):10.

16. Hoyt J, Landuwulang CUR, Ansariadi, Ahmed R, Burdam FH, Bonsapia I, et al. Intermittent screening and treatment or intermittent preventive treatment compared to current policy of single screening and treatment for the prevention of malaria in pregnancy in Eastern Indonesia: acceptability among health providers and pregnant women. Malar J. 2018;17(1):341.

17. Eradication M. Speech by Tedros Adhanom Ghebreyesus, WHO Director-General. 2019. Available at: https://www.who.int/dg/speeches/ detail/malaria-eradication. Accessed on 7 May 2020.

Cite this article as: Prawira-Putra A, Lukito T, Ahmed R. Strategies for the prevention of malaria in pregnancy in Indonesia in the COVID-19 pandemic era. Int J Community Med Public Health 2020;7:2862-4. 